\title{
Regional Remagnetization of IRISH CARboniferous CaRbonates Dates VaRiscan Orogenesis, Not Zn-PB Mineralization
}

Jamie J. Wilkinson, Katie Vowles, Adrian R. Muxworthy, and Conall Mac Niocaill

\section{Supplementary Online Material}

\section{Scanning Electron Microscopy}

Scanning electron microscope backscattered electron images (acquired using the Cameca SX500 at the Natural History Museum, London) illustrating textural relationships between carbonate host rock phases and trace oxides/sulfides.
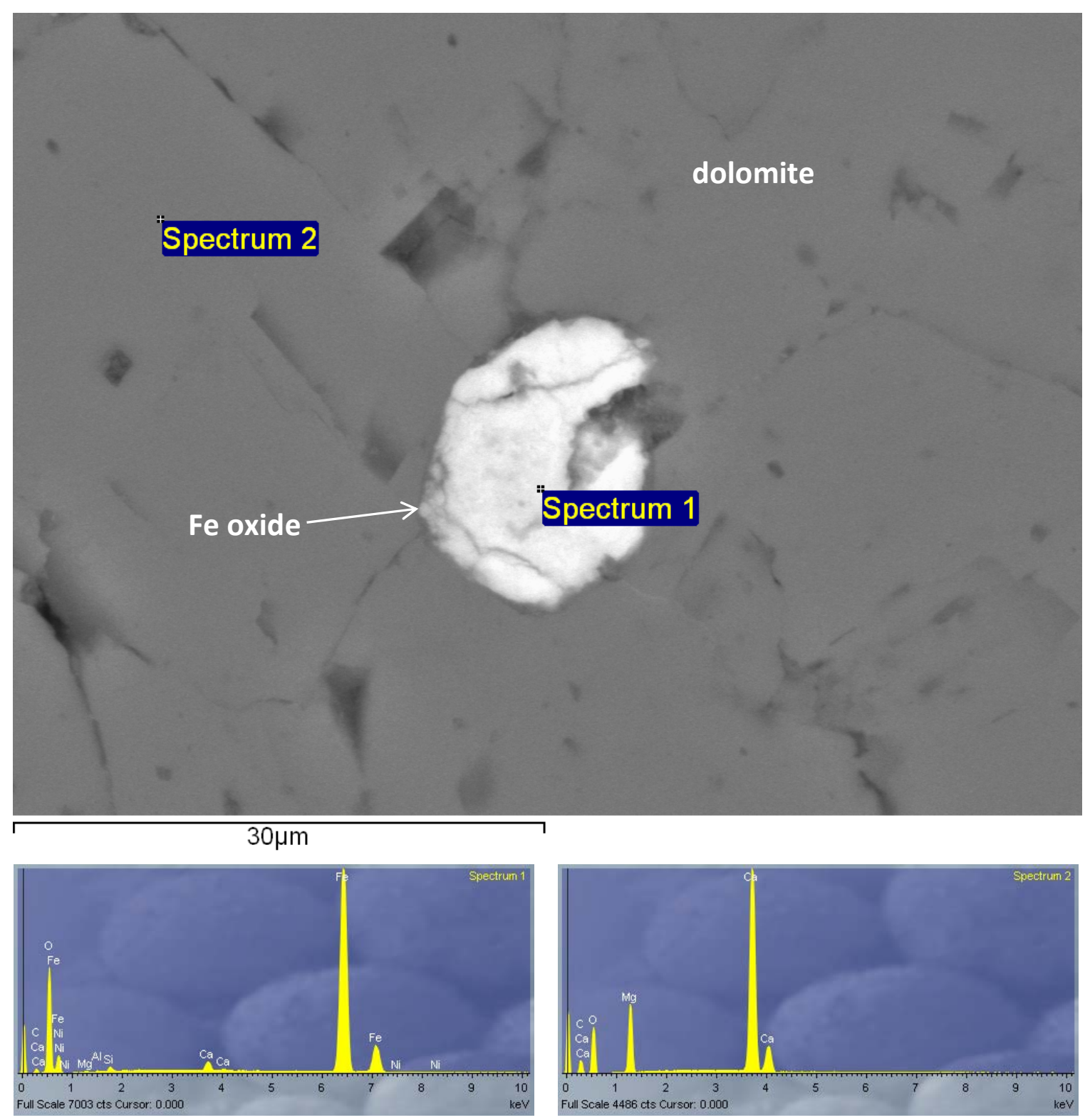

Figure DR1. Pervasively dolomitized limestone from Kells East (sample KE-4). Small Fe oxide grains are associated with grain boundaries and are intergrown with dolomite. EDS spectra confirm the phase identifications. 


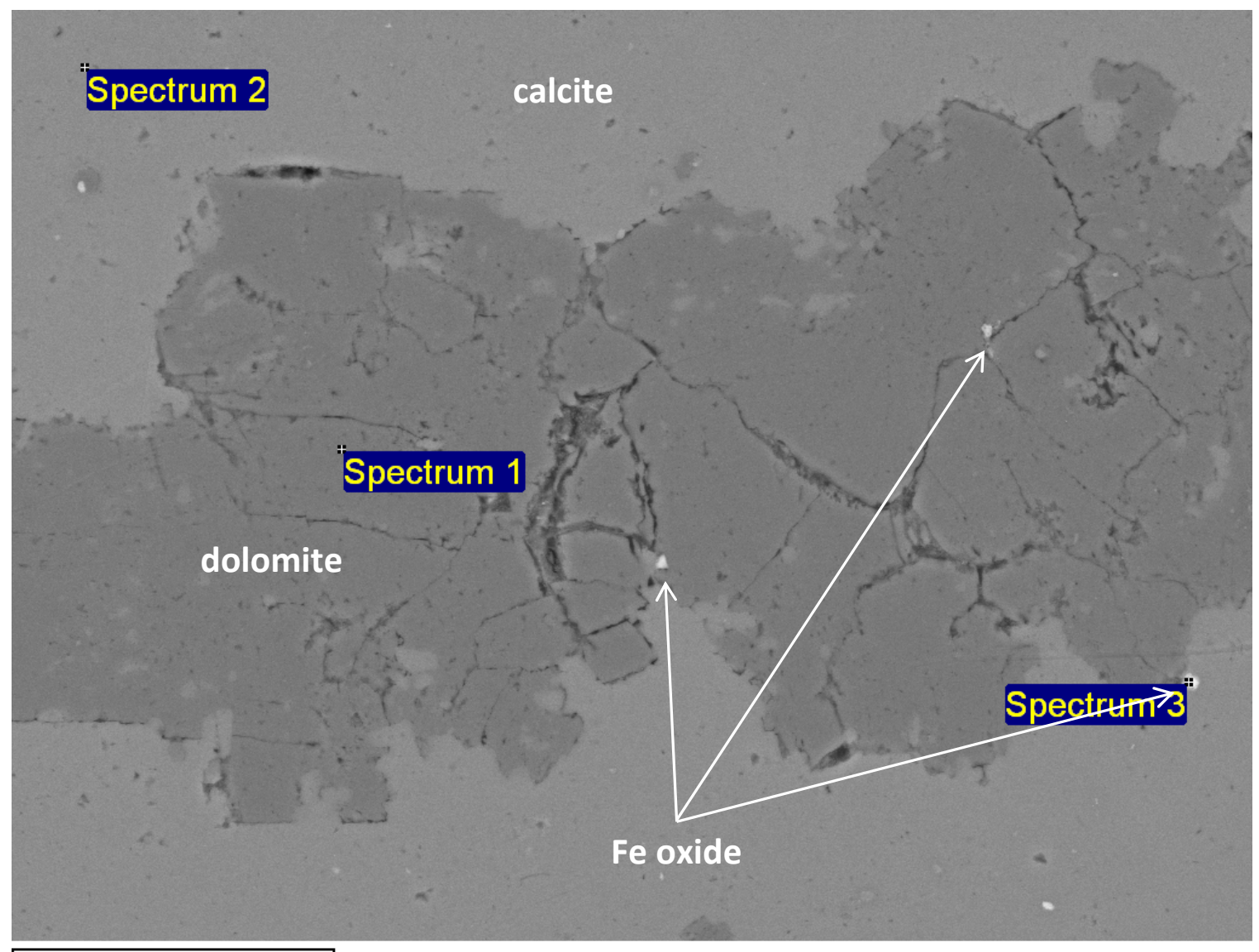

$100 \mu \mathrm{m}$
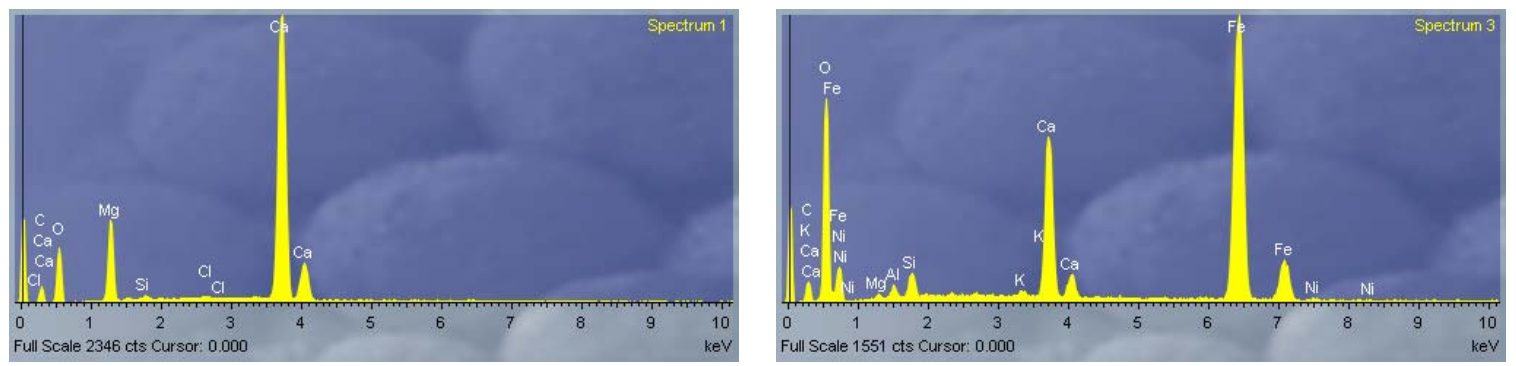

Figure DR2. Dolomite band in partially dolomitized limestone from Tory Hill (sample TH-6). Very small Fe oxide grains are associated with grain boundaries between dolomite crystals and along the contact with surrounding calcite. Relics of calcite within the dolomite indicate that the dolomite has replaced it during its formation. EDS spectra confirm the phase identifications. Spectrum 3 contains peaks for $\mathrm{Ca}, \mathrm{Mg}, \mathrm{K}, \mathrm{Al}$ and Si due to beam overlap with neighbouring phases (calcite, dolomite and trace clays). 


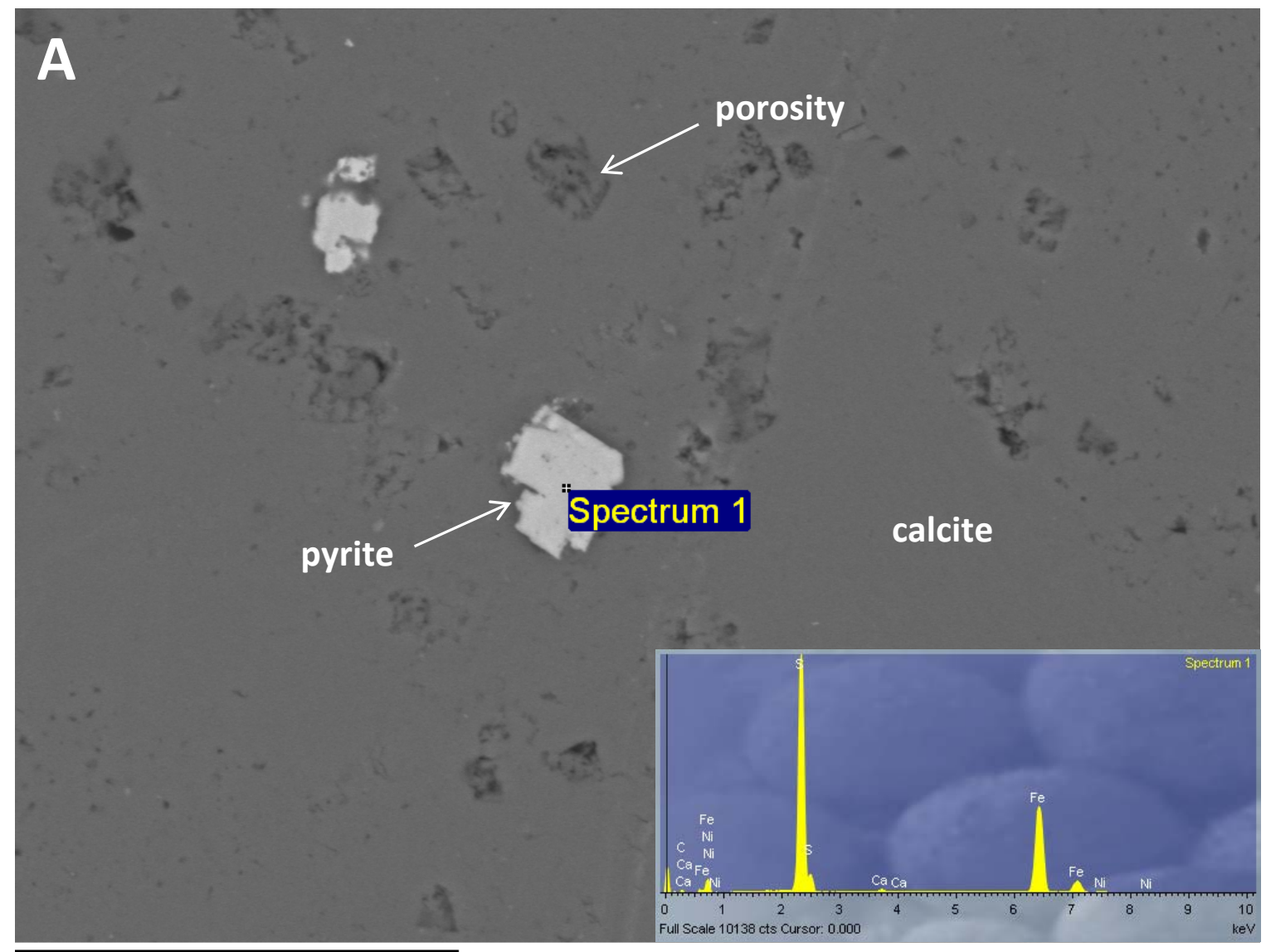

$100 \mu \mathrm{m}$

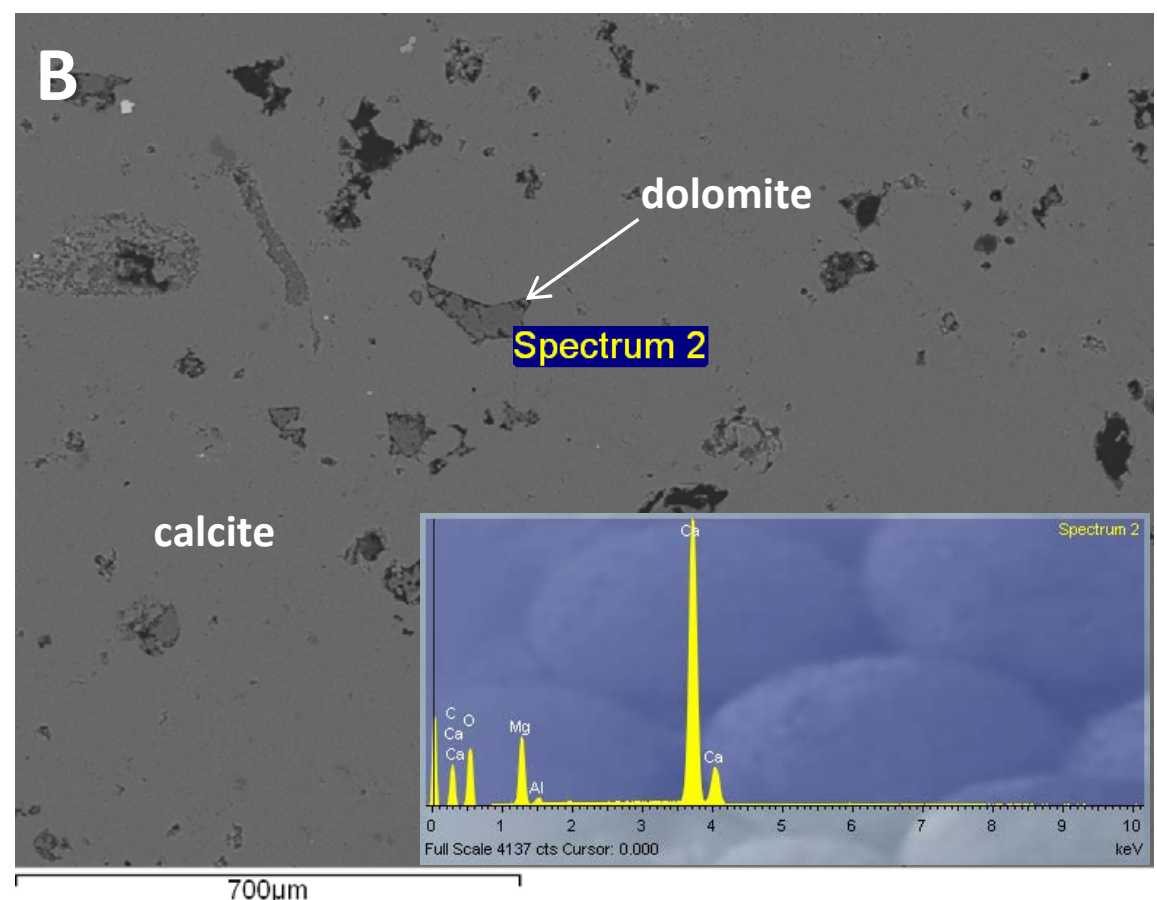

Figure DR3. A. Small sub- to euhedral pyrite grains associated with intergranular porosity in limestone from Newmarket Bypass (sample NB-4). B. Minor dolomite is present, infilling voids between calcite crystals. EDS spectra confirm the phase identifications. 

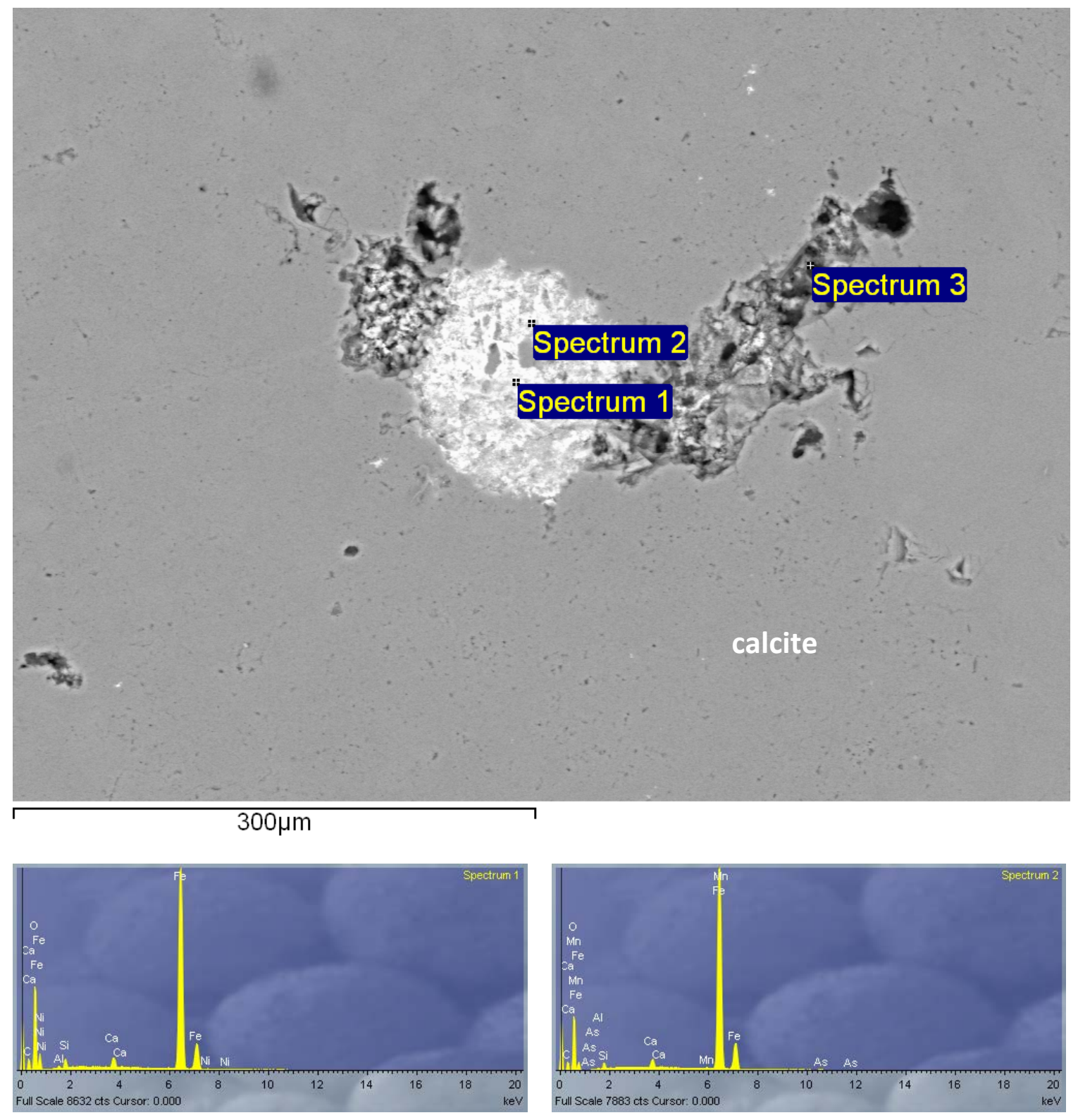

Figure DR4. Composite $\mathrm{Fe}(\mathrm{Mn}, \mathrm{Ni}, \mathrm{As})$ oxide grain in dissolution porosity with trace clays in limestone, Swords Roundabout (sample SR-2). Heterogeneous backscatter intensity and EDS spectra indicate a complex oxide intergrowth. 

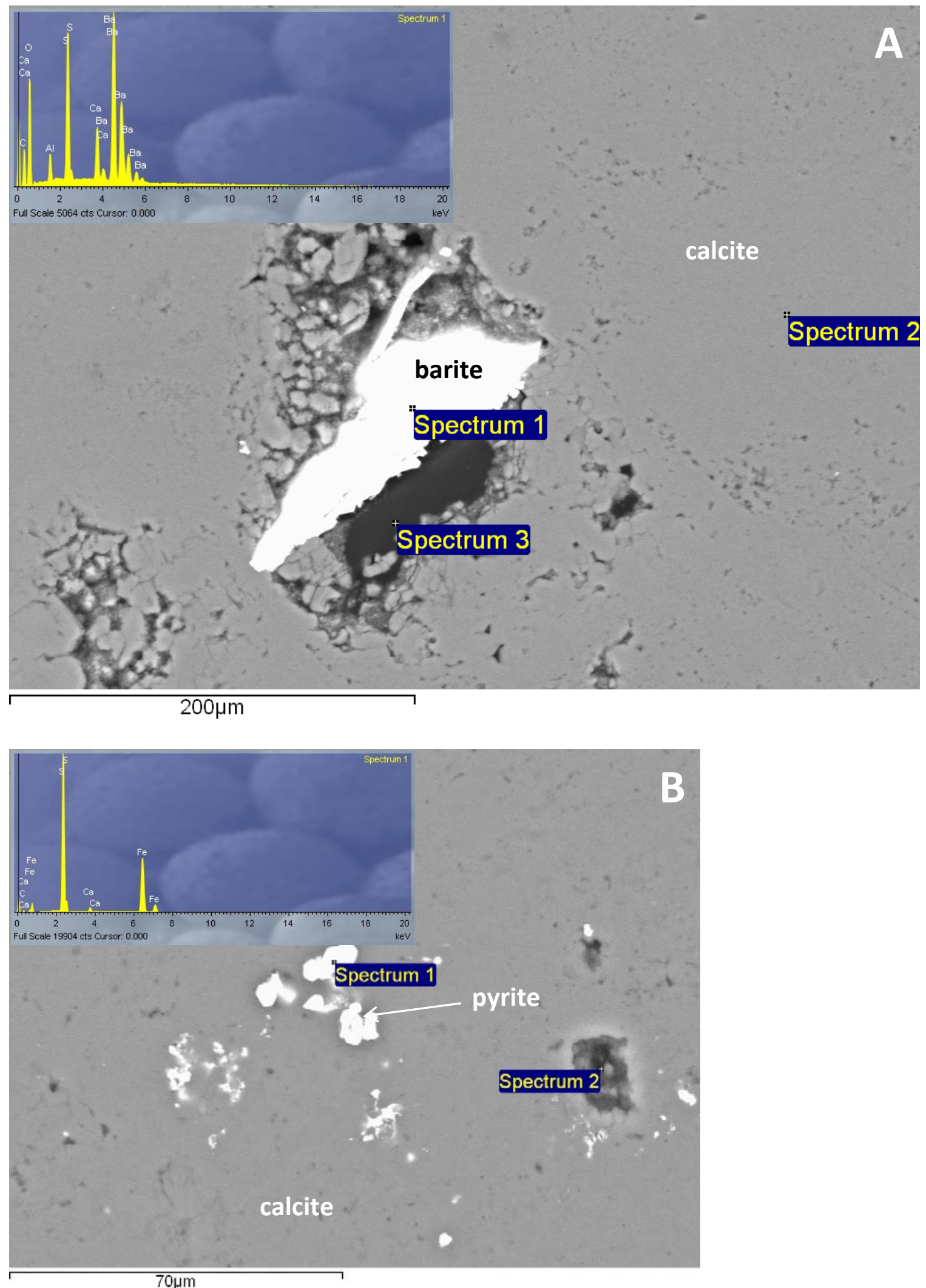

Figure DR5. A. Large barite grain within intergranular porosity in limestone from Trim Quarry (sample TQ-1). B. Euhedral disseminated pyrite infilling pores and replacing the host rock in the same sample. 

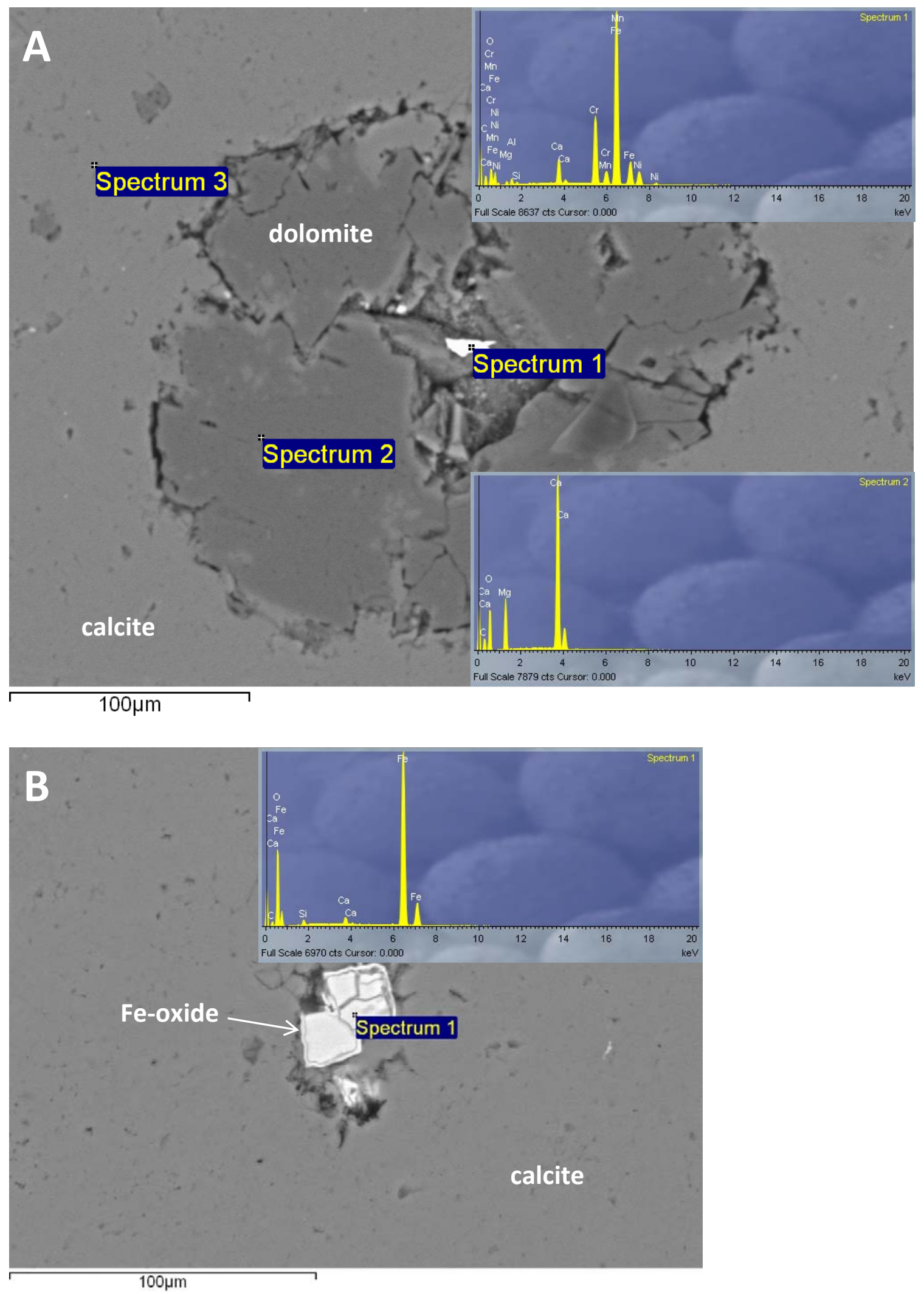

Figure DR6. A. Chrome spinel (possibly chromian magnetite, including $\mathrm{Mn}, \mathrm{Ni}$ ) associated with dolomite after ?crinoid ossicle within limestone from Cloughjordan North (sample CN5). B. Subhedral Fe oxide (after pyrite?) in dissolution pore in the same sample. 


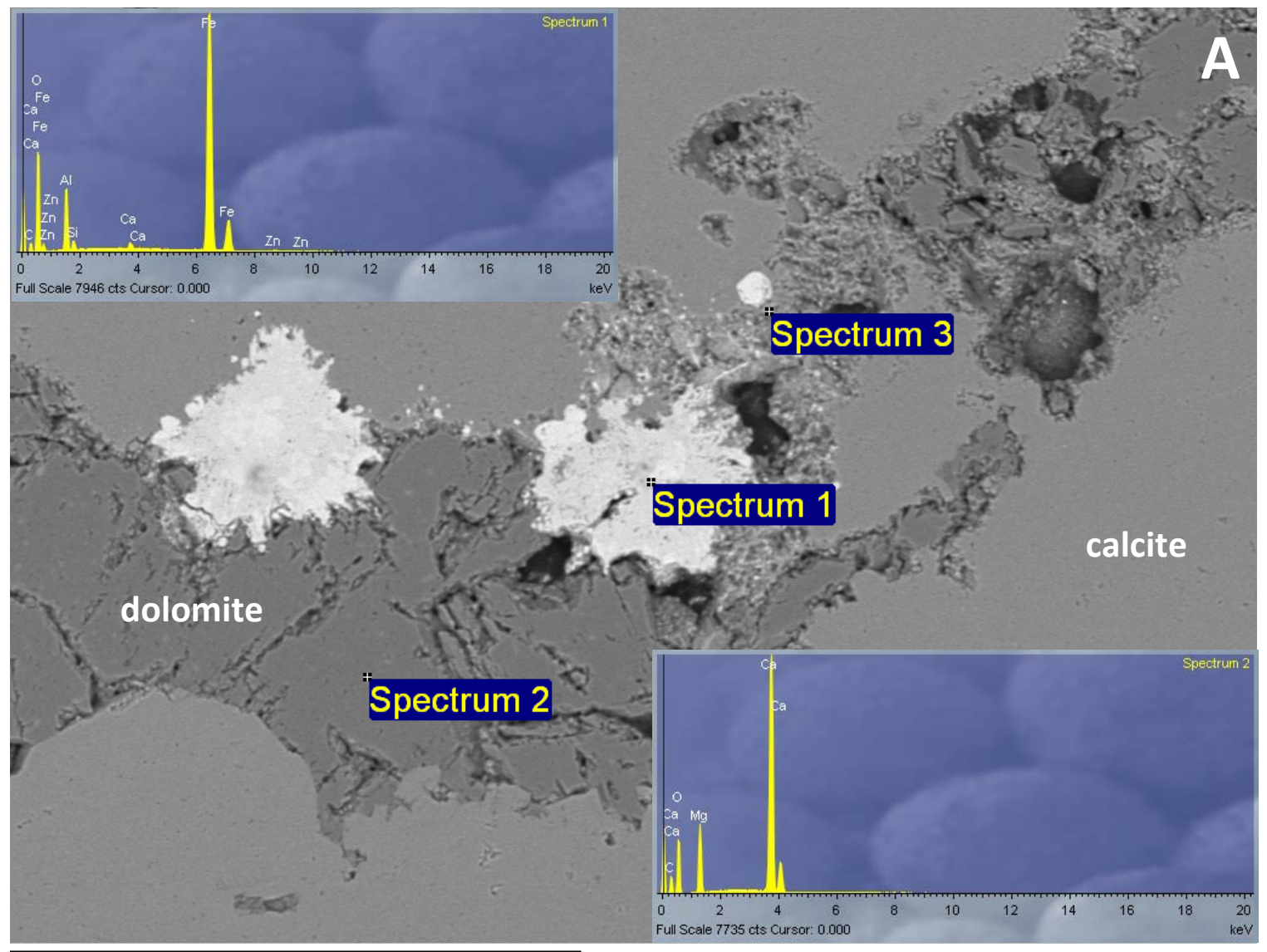

$700 \mu \mathrm{m}$

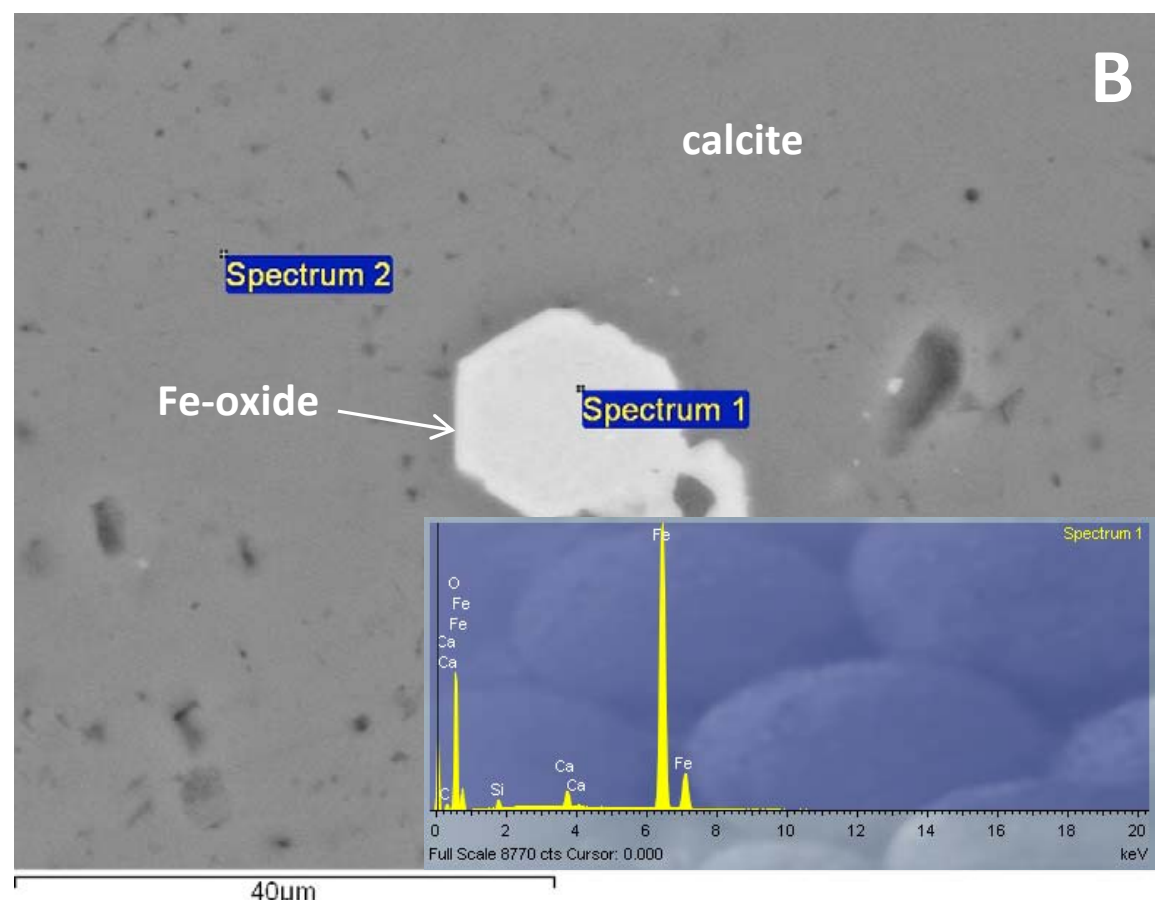

Figure DR7. A. Anhedral patches of $\mathrm{Fe}(-\mathrm{Zn})$ oxide and probable clay associated with dolomite vein cutting limestone from Ballykane Hill (sample BH-8). B. Hexagonal form of Fe oxide within limestone in the same sample 


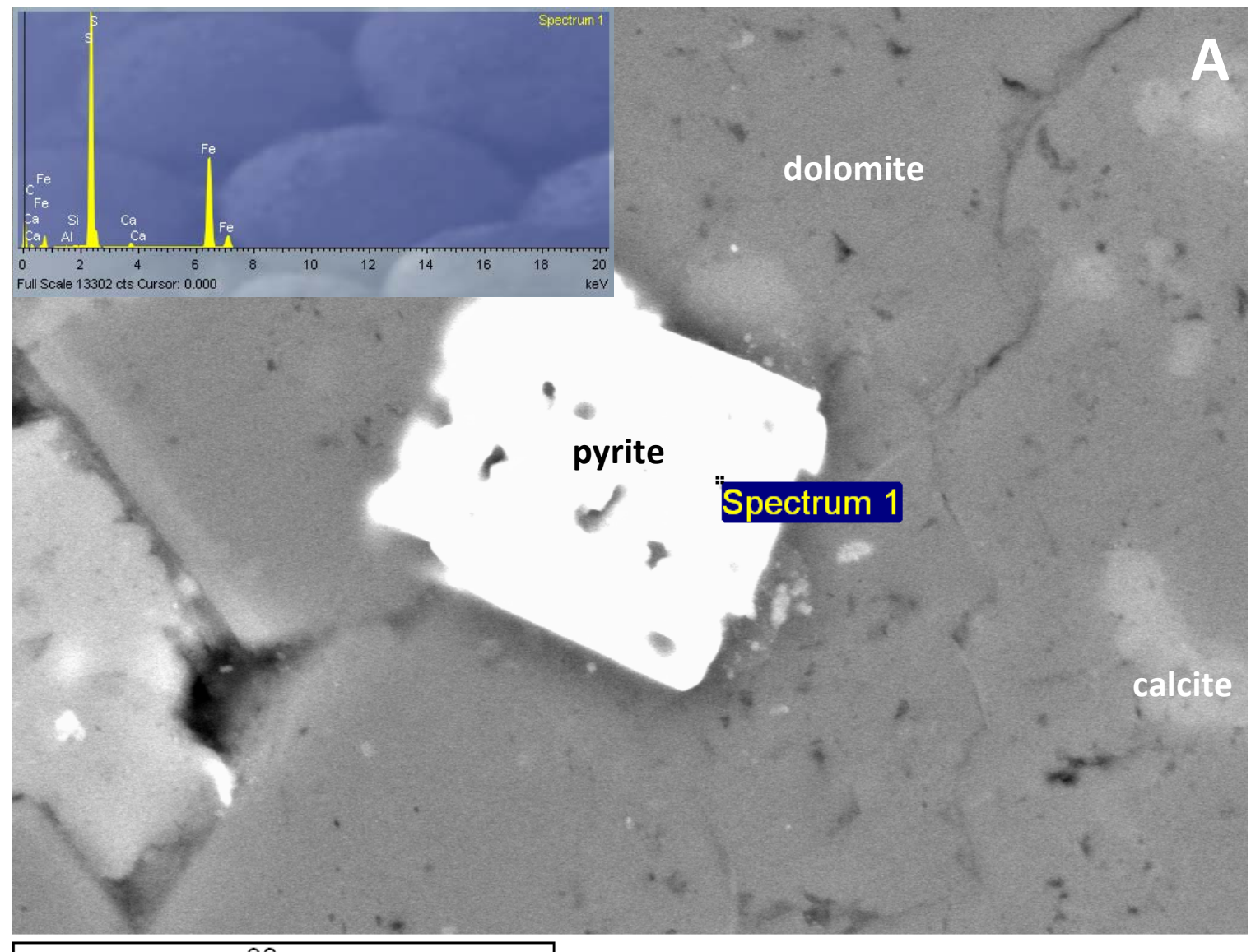

$30 \mu \mathrm{m}$

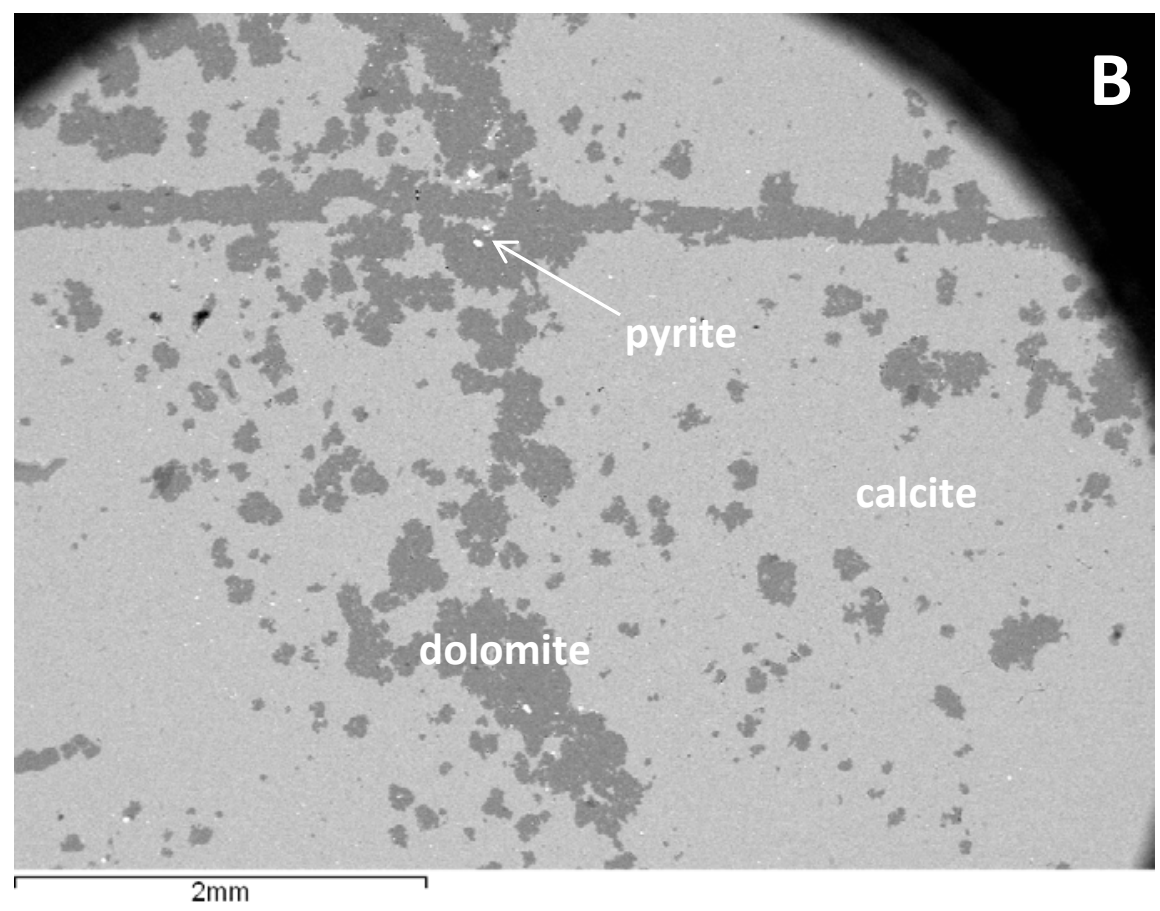

Figure DR8. A. Euhedral pyrite intergrown with dolomite that has replaced calcite in partially dolomitized limestone from Knockshangarry Quarry (sample KQ-3). B. Veinlet and patchy dolomitization of limestone in the same sample; fine pyrite is associated with 
dolomite.
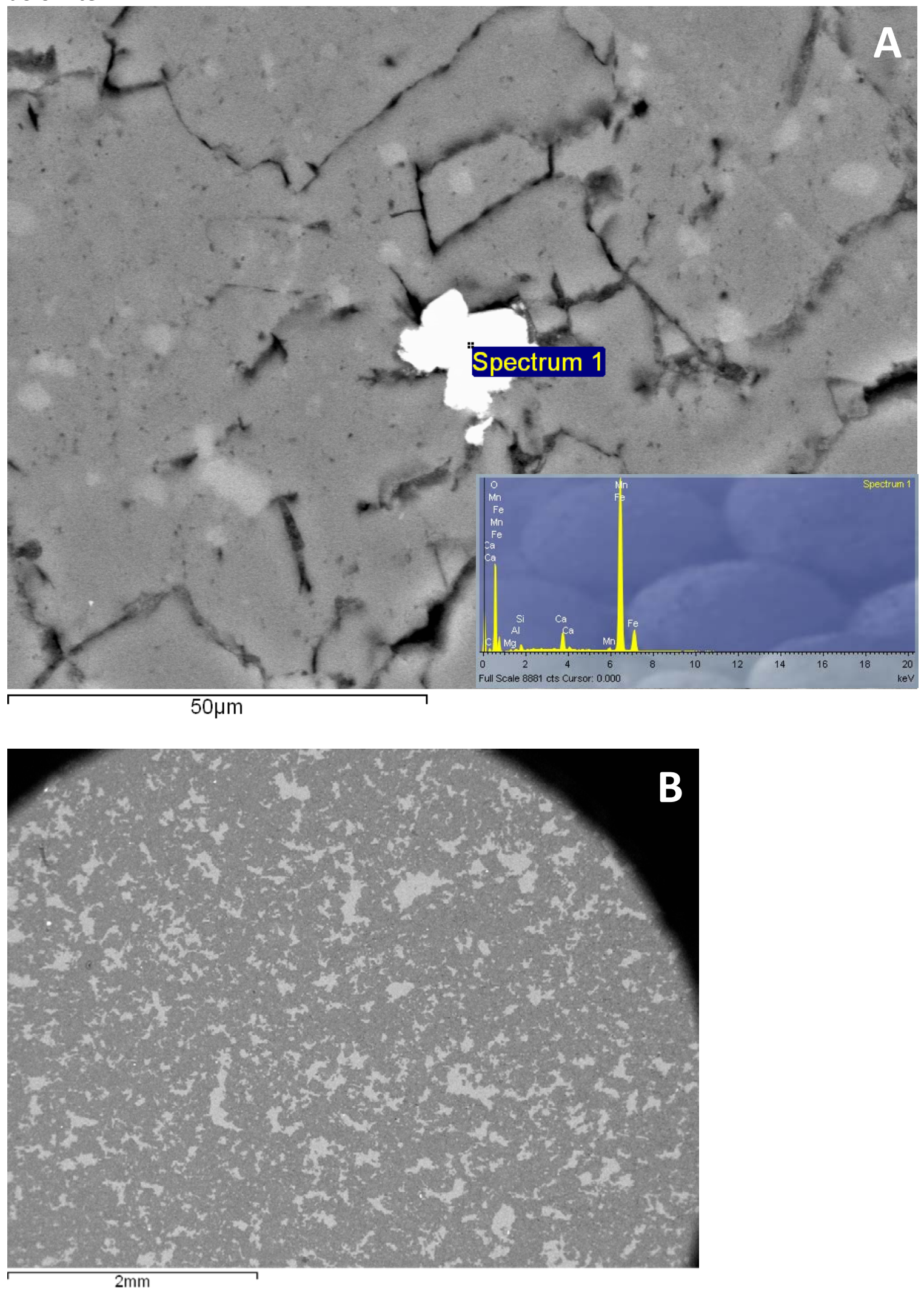

Figure DR9. A. Euhedral Fe(-Mn) oxide situated on grain boundaries between dolomite crystals in strongly dolomitized limestone from Barrow River (sample BR-3). B. Pervasive 
dolomitization of limestone in the same sample.

\section{Rock magnetic analysis}

During most of the thermomagnetic analysis, most samples displayed the same behavior (Type A, Fig. DR10a), that is on heating in helium a new strongly magnetic phase starts to form at around $400^{\circ} \mathrm{C}$, which has a Curie temperature close to that of stoichiometric magnetite $\left(\sim 560-580{ }^{\circ} \mathrm{C}\right.$, Table DR1). On cooling, a single magnetic phase with Curie temperature similar to that of magnetite is generated (Table DR1, Fig. DR10a): the curves are not reversible. This behavior is most likely due to the oxidation of pyrite to magnetite during heating, and has been reported previously for limestones (e.g., Gong et al., 2008). This indicates that the thermal demagnetization results higher than $\sim 400^{\circ} \mathrm{C}$ are not stable. In some cases, the cooling curve displays a distinct secondary Curie temperature in the region $300-$ $320{ }^{\circ} \mathrm{C}$ (Type B, Fig. DR10b, Table DR1), which is likely due to the formation of pyrrhotite from pyrite: heating was in a $\mathrm{He}$ atmosphere and there was possibly insufficient oxygen for complete oxidation of pyrite and formation of magnetite. Some of the samples had magnetisation dominated by a diamagnetic signal, and the Curie temperature could not be determined meaningfully (Type C, Fig. DR10c, Table DR1).
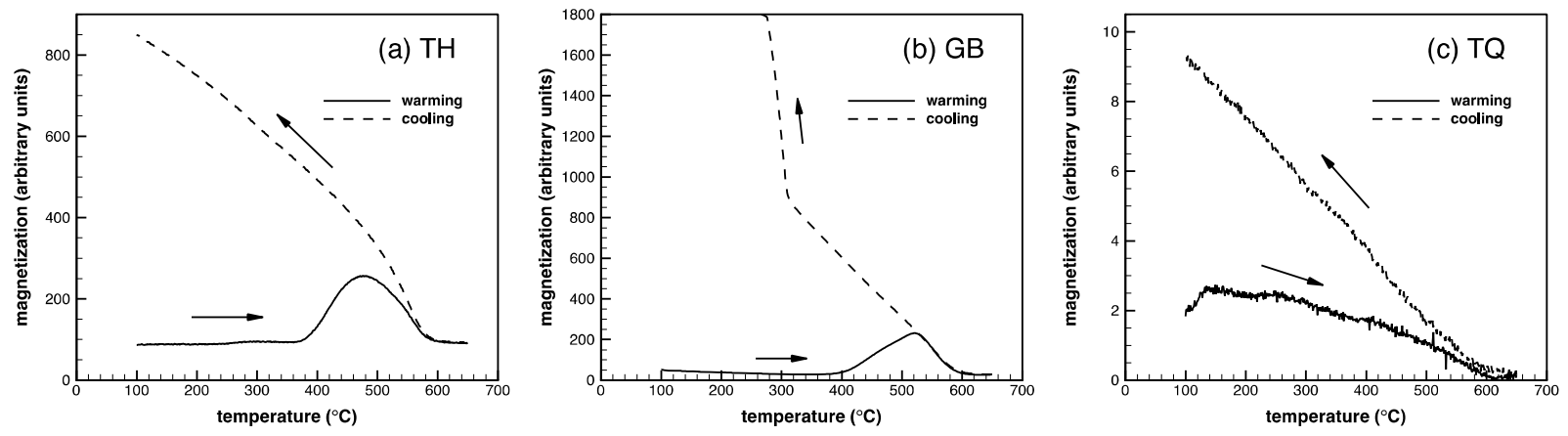

Figure DR10. Thermomagnetic curves for samples: a) TH (Type A); b) GB (Type B); and c) TQ (Type C), displaying behavior types A-C respectively.

The samples' hysteresis properties are summarised in Table DR1. The samples' hysteresis loops were generally wasp-wasted, which is indicative of either a two-phase magnetic assemblage or the presence of thermally activated single domain (SD) behaviour, i.e., superparamagnetism (SP). For magnetite, the critical SP threshold size is approximately 30 $\mathrm{nm}$, indicating that there is a significant proportion of nanometric material in the samples. Due to the weakness of the samples' magnetic signal, the hysteresis loops were rather noisy. 
Table DR1. Summary of the rock magnetic measurements on the samples. Standard hysteresis parameters are given: saturation magnetization, $M_{S}$, saturation remanence $M_{R S}$, coercive force, $B_{C}$, and coercivity of remanence, $B_{C R}$.

\begin{tabular}{ccccccc}
\hline locality & \multicolumn{3}{c}{ hysteresis data } & \multicolumn{3}{c}{ thermomagnetic data } \\
& $B_{C}(\mathrm{mT})$ & $B_{C R}(\mathrm{mT})$ & $M_{R S} / M_{S}$ & warming $T_{C}\left({ }^{\circ} \mathrm{C}\right)$ & $\begin{array}{c}\text { cooling } T_{C} \\
\left({ }^{\circ} \mathrm{C}\right)\end{array}$ & class \\
\hline BR & 5.8 & 43 & 0.22 & 562 & 559 & $\mathrm{~A}$ \\
CN & $\ldots{ }^{1}$ & $\ldots{ }^{1}$ & $\ldots{ }^{1}$ & 565 & 562 & $\mathrm{~A}$ \\
BH & 4.9 & 114 & 0.16 & 575 & 570 & $\mathrm{~A}$ \\
BQ & $\ldots{ }^{1}$ & $\ldots{ }^{1}$ & $\ldots{ }^{1}$ & $\ldots{ }^{2}$ & $\ldots{ }^{2}$ & $\mathrm{C}$ \\
ES & $\ldots{ }^{1}$ & $\ldots{ }^{1}$ & $\ldots{ }^{1}$ & $\ldots{ }^{1}$ & $\ldots{ }^{1}$ & $\ldots{ }^{1}$ \\
FQ & $\ldots{ }^{1}$ & $\ldots{ }^{1}$ & $\ldots{ }^{1}$ & $\ldots{ }^{1}$ & $\ldots$ & $\ldots{ }^{1}$ \\
GB & 9.3 & 30 & 0.16 & 583 & $579 \& 309$ & $\mathrm{~B}$ \\
KE & 11.4 & 65 & 0.40 & 571 & 582 & $\mathrm{~A}$ \\
KQ & 6.3 & 42 & 0.23 & $\ldots{ }^{2}$ & $\ldots{ }^{2}$ & $\mathrm{C}$ \\
NB & 3.9 & 35 & 0.37 & $\ldots{ }^{2}$ & $\ldots{ }^{2}$ & $\mathrm{C}$ \\
RT & 3.0 & 31 & 0.13 & 579 & $574 \& 304$ & $\mathrm{~B}$ \\
SR & 2.0 & 46 & 0.04 & $\ldots{ }^{2}$ & $\ldots{ }^{2}$ & $\mathrm{C}$ \\
TH & 6.5 & 404 & 0.25 & 576 & 572 & $\mathrm{~A}$ \\
TQ & 4.1 & 44 & 0.22 & $\ldots{ }^{2}$ & $\ldots{ }^{2}$ & $\mathrm{C}$ \\
\hline
\end{tabular}

${ }^{1}$ Sample too weak to measure accurately.

${ }^{2}$ Poorly defined

Reference

Gong Z., Dekkers M. J., Dinares-Turell J., and Mullender T. A. T. (2008) Remagnetization mechanism of Lower Cretaceous rocks from the Organya Basin (Pyrenees, Spain). Studia Geophysica Et Geodaetica 52(2), 187-210. 